\title{
AUDITORIA DE PESSOAL - Uma Experiência Nova na Administração Pública Brasileira
}

HENRIQUE GOMES DE ALMEIDA

Técnico de Administração do IPASE

MIGUEL LOPES MACIEL

Técnico de Administração do INCRA

\begin{abstract}
SUMÁRIO : 1 . O Sistema de Pessoal Civil da Administração Federal e sua contribuição para o desenvolvimento da administração de pessoal. 2. A necessidade da avaliação crítica dos programas de trabalho e sua consonância com as diretrizes gerais de uma política de pessoal global. 3. A necessidade da Auditoria e a figura do Auditor: depoimentos técnicos que justificam a "Técnica a Serviço do Controle". 4. Auditoria de Pessoal e sua contribuição para a permanente atualização de uma administração sistêmica.
\end{abstract}

A partir de 1967, com o advento do Decreto-lei 200, inúmeras transformações foram impostas à administração pública com vistas à conquista de um padrão de eficiência capaz de acompanhar o desenvolvimento nacional.

Os objetivos da Reforma Administrativa - melhor serviço público, decisões mais rápidas, redução dos gastos administrativos bem como de custos nas empresas do Estado - só poderão ser alcançados na medida em que os recursos humanos se apresentarem tecnicamente capacitados para a produção de modificações profundas, dentre as quais a alteração do comportamento dos dirigentes.

Para que venham a ser atingidos os objetivos da Reforma Administrativa, necessário se tornava o surgimento de uma politica de pessoal que permitisse a profissionalização do servidor público com observância de padrões de valorização e dignificação da função pública, fatores de manutenção e aquisição de recursos humanos qualificados para assimilar o impacto que a 
4) Determinar a solução. Isto é, tomar a decisão. Vale lembrar que nem sempre a solução perfeita ou quase perfeita é a escolhida. Os fatos, as disponibilidades e a exeqüibilidade naquele momento determinam a decisão.

\section{5) Agir para executar a solução adotada.}

No concernente ao trabalho do Cadastro de Pessoal, as quatro primeiras etapas já foram vencidas.

Definiu-se o objetivo do Cadastro e o seu propósito. Decidiu-se o que se devia registrar e, depois, como registrar e o método a ser utilizado no registro. Feito isso, elaborou-se os meios de captação de dados, já sabido, lógico, ser o método de computação eletrônica de dados, nos quais se contém a decisão do que pedir, como pedir e a quem pedir. Procurou-se nessa decisão simplificar o máximo possível, sem comprometer o objetivo final e a eficiência da execução do método escolhido.

A quinta etapa foi iniciada com a remessa do MANUAL DE CADASTRO aos Órgãos Setoriais e Seccionais do SIPEC. Outras atividades de ordem interna estão em plena execução. No caso específico do CADASTRO, esta etapa é contínua e, teoricamente, jamais acabará, porquanto a implantação do CADASTRO e a sua constante atualização de certa forma, constituem forma de ação permanente para executar a solução adotada.

É mister, é curial, é imprescindível contar o DASP com a colaboração integral de todos - começando pelos dirigentes dos órgãos integrantes do SIPEC - a fim de ter o mais rapidamente possível - e de forma eficaz - concluído o Cadastro Central

É bom lembrar, contudo, estar o funcionamento do Cadastro Central dependente da montagem e execução dos Cadastros Setoriais e Seccionais. Eles constituirão a pedra angular da ad-

Mesmo requerendo muito esforço, deve-se fazê-lo; não como promoção de ninguém ou de nenhum órgão, mas em prol da FUNCIONALISMO. 


\title{
AUDITORIA DE PESSOAL - Uma Experiência Nova na Administração Pública Brasileira
}

\author{
HENRIQUE GOMES DE ALMEIDA \\ Técnico de Administração do IPASE \\ MIGUEL LOPES MACIEL \\ Técnico de Administração do INCRA
}

\begin{abstract}
SUMÁRIO : 1. O Sistema de Pessoal Civil da Administração Federal e sua contribuição para o desenvolvimento da administração de pessoal. 2. A necessidade da avaliação crítica dos programas de trabalho e sua consonância com as diretrizes gerais de uma politica de pessoal global. 3. A necessidade da Auditoria e a figura do Auditor: depoimentos técnicos que justificam a "Técnica a Serviço do Controle". 4. Auditoria de Pessoal e sua contribuição para a permanente atualização de uma administração sistêmica.
\end{abstract}

A partir de 1967, com o advento do Decreto-lei 200, inúmeras transformações foram impostas à administração pública com vistas à conquista de um padrão de eficiência capaz de acompanhar o desenvolvimento nacional.

Os objetivos da Reforma Administrativa - melhor serviço público, decisões mais rápidas, redução dos gastos administrativos bem como de custos nas empresas do Estado - só poderão ser alcançados na medida em que os recursos humanos se apresentarem tecnicamente capacitados para a produção de modificações profundas, dentre as quais a alteração do comportamento dos dirigentes.

Para que venham a ser atingidos os objetivos da Reforma Administrativa, necessário se tornava o surgimento de uma politica de pessoal que permitisse a profissionalização do servidor público com observância de padrões de valorização e dignificação da função pública, fatores de manutenção e aquisição de recursos humanos qualificados para assimilar o impacto que a 
tecnologia produziu na administração e desse progresso retirar a máxima contribuição.

Acompanhando a evolução administrativa, determinou o legislador que as atividades de pessoal fossem organizadas sob a forma de sistema, sujeitando todas as unidades organizacionais, que cuidem de pessoal, ao comando técnico de um órgão central, atribuindo-se ao seu dirigente a responsabilidade pelo fiel cumprimento de leis e regulamentos bem como pelo seu funcionamento eficiente e coordenado, exigindo-se, em contrapartida, da direção de todos os órgãos integrantes, o dever de atuação para a conquista do rendimento máximo com diminuição dos custos operacionais.

Em outubro de 1971, com base no Decreto-lei n. ${ }^{\circ}$ 200/67, - Poder Executivo instituiu o Sistema de Pessoal Civil da Administração Federal, definindo sua composição e dando ao órgão central - Departamento Administrativo do Pessoal Civil - competência para o estudo, formulação de diretrizes, orientação normativa, coordenação, supervisão, controle e fiscalização específica de assuntos concernentes ao pessoal civil da administração
federal.

Estava dado o grande passo. Agora, poderia o governo deflagrar uma política de pessoal dinâmica, capaz de atingir a todo o universo da administração pública dentro de um ordenamento normativo em que a técnica viria substituir o empirismo.

A partir da implantação do SIPEC, dentro de diretrizes gerais formuladas pelo órgão central, tornou-se possível o surgimento de uma nova política de pessoal, cujos resultados de há muito tempo deixaram o campo da especulação sobre sua viabilidade técnica para se apresentarem como conquista altamente positiva no contexto da administração pública.

Pretende o sistema, "uma entidade - conceitual ou física - composta de partes inter-relacionadas, interagentes ou interdependentes" segundo Hanika (1), perseguir um objetivo comum - maior eficiência do serviço público - o que implicará, necessariamente, mudança de comportamento de seus integrantes.

Essa nova forma de administração de pessoal exige que se conheça até que ponto o trabalho das diversas áreas se ajusta à
orientação do órgão central.

É necessário que a participação dos órgãos, perifericamente situados, se faça não apenas por imperativo legal mas essen-

R. Serv. públ., Brasília, 109 (3) jul./set. 1974 
cialmente por participação ativa, por integração completa aos objetivos a serem alcançados.

A verificação de cada unidade de pessoal, envolvendo a análise de sua estrutura e seu posicionamento no contexto aa crganização, bem como o modo pelo qual se desenvolvem suas operações e a capacitação dos recursos humanos existentes, tornou-se imprescindivel para melhor conhecimento do sistema, permitindo, quando for o caso, alterações tendentes à correção de desvios.

É fato que uma administração dinâmica exige análise das funções básicas que exercita para identificação de possiveis desajustamentos, possibilitando, dessa forma, adoção das medidas corretivas apropriadas. Por outro lado, essa avaliação e análise permitirá o recolhimento de experiências válidas para sua divulgação entre os integrantes do sistema.

A Auditoria - instituída pelo Decreto n. 68.992 , de 28 de julho de 1971 - representa um mecanismo imprescindivel ao desenvolvimento do sistema, através do qual o Governo pode desenvolver a atual política de pessoal, tendo por principal escopo não só dignificar o exercício da função pública como prover a administração de servidores realmente capacitados para o desempenho de suas tarefas.

A seu turno, no atingimento do ideal de "concessão de maior autonomia aos dirigentes e chefes da administração de pessoal, visando a fortalecer a autoridade do comando em seus diferentes graus e a dar-Ihes efetiva responsabilidade pela supervisão e rendimento dos serviços sob sua jurisdição" (item VIII, Art. 94, Dec.-Lei 200/67) a Auditoria poderá exercer valiosa contribuição, constatando diretamente o tratamento que cada organização concede ao seu dirigente de pessoal.

O rápido volver a um passado não muito remoto, nos mostra que muitas distorções existentes no serviço público podem ser atribuídas a administradores que relegaram suas unidades de pessoal a planos inferiores, sem a visão do quanto representariam para as atividades-fim o correto posicionamento do órgão de pessoal e o prestígio e qualificação técnica que deveria ter o seu responsável.

O incontestável é que, no atual estágio, nada justifica, a Fartir do desenvolvimento dessa nova política, que órgãos integrantes do sistema ajam de forma estanque, ao sabor de diretri- 
zes próprias, quase sempre distanciadas das normas gerais delineadas pelo Governo.

Não data de muito a época em que, sem qualquer instrumento de controle, organismos da esfera federal traçavam sua própria política, nesse campo, à mercê dos seus próprios interesses, esquecidos de que o serviço público é um todo, diversificado, apenas, pela gama de atividades que ao Estado cabe desenvolver em benefício do contribuinte.

Sem se atentar para as repercussões de âmbito geral, tais como custo de pessoal, ingresso de mão-de-obra desqualificada, estímulo ao descontentamento entre funcionários mais antigos, cometeram-se alguns abusos que tentaram estratificar-se com o decorrer do tempo.

A guisa de exemplo, vale, neste passo, registrarmos tópico da aula proferida em 1968, em curso de Aperfeiçoamento de Assessores, sob o tema "Administração de Pessoal e Orçamento", pelo atual Presidente do Conselho Federal de Técnicos de Administração, Murilo Moreira da Silva, quando alertava:

"Não seria demais lembrar os perigos da volta ao cáos de onde saimos de uma feita a duras penas e que, se bem nos lembramos, guardava muita semelhança com alguns quadros atuais. A falácia da substituição dos quadros por tabelas, quaisquer tabelas; da desmoralização da estabilidade e até do vínculo empregatício diante da preferência, em moda, pelo eventual; a enganosa idéia, em franco desenvolvimento, de substituição dos cargos, em qualquer área e nível de responsabilidade pela novidade da prestação de serviços, muito cedo poderão transformarse em problemas graves para o Estado e em novas decepções. Realmente, vive o Governo preocupado com as nomeações de concursados, para cargos modestamente remunerados, supondo estar racionalizando ou modernizando o processo de administração de pessoal ou, ainda, economizando. Mas estaria esta mesma ciente dos males a que se poderá chegar com a prática deformada das admissões mediante recibo, feitas sem comprovação da capacidade e sem respeito a qualquer sistema de remuneração? Que tipo de economia estaríamos obtendo e que eficiếncia estaríamos comprando?" (2)

Relativamente a essa categoria de servidores - pagos mediante recibo - o Prof. João Luiz Ney, em excelente trabalho,
faz a seguinte menção: 
"Um levantamento do número de pessoas nessa situação, nos vários órgãos da Administração Federal, revelaria existir atualmente um novo e exótico Quadro de Pessoal em competição com o corpo de pessoal permanente. Argumento para essa manobra é que a colaboração eventual à Administração Pública Federal sob a forma de prestação de serviços retribuída mediante recibo, não concretizará, em hipótese alguma, vínculo empregatício com - Serviço Público Civil, e, por isso, somente poderá ser atendida por dotação não classificada na rubrica "Pessoal" e nos limites estabelecidos nos respectivos programas de trabalho.

Paga-se, assim, a pessoal com o que não é de pessoal para se convencer que não se emprega pessoal. Malabarismo engenhoso para adoção de subterfúgio apressado e oneroso que poderia e pode ser evitado com treinamento intensivo e compulsório devidamente programado." (3)

Estes depoimentos são bem uma imagem do que vinha ocorrendo em nosso serviço público, não se podendo dizer que, embora em pequena escala, tais fatos ainda não aconteçam.

Normas disciplinadoras existem, e de vigência indiscutível. Todavia, como saber-se de sua eficácia, se não por meio de um dispostivo de controle que, quando acionado, ofereça uma imagem da organização no que tange à área de pessoal?

Com o propósito de proceder a este acompanhamento vale repetirmos - é que foi criada a Auditoria, em sentido lato, uma "Técnica a Serviço do Controle", como ensina o Ministro Iberê Gilson. (4)

Mas a Auditoria de Pessoal, em seu elenco de objetivos, não se prende, tão-somente, à idéia de controle ou de fiscalização. Está presente, também, a de orientação e mesmo de "prestação de assistência técnica aos órgãos fiscalizados, visando à correção de falhas, à melhoria das condições operacionais ou à atualização de métodos de trabalho." (art. 5.0 letra "l" do Decreto n. ${ }^{\circ} 68.992 / 71$ ).

A noção de controle, por auditoria, foi muito bem focalizada pelo Professor José da Costa Boucinhas, da Faculdade de Ciências Contábeis da Universidade de São Paulo, ao ensejo do Primeiro Seminário de Auditoria e Controles na Administração Pública, realizado naquela cidade, em 1969. Disse o citado mestre : 
"Para que o controle seja efetivo, e sua eficácia e necessidade reconhecidas, é necessário que haja uma consciência coletiva e que seja aceito como fato normal, tanto pelo controlado como pelo controlador.

Quem exerce o controle deve estar munido da humildade própria daquele que executa uma tarefa de interesse social e quem sofre o controle não pode sentir-se melindrado, pois a ação controladora beneficia a todos e tem uma finalidade preventiva e não, necessariamente, corretiva ou punitiva. Dentro desse contexto e atendidas as naturais reações psicológicas o auditor deve possuir um alto grau de equilíbrio emocional, senso de autocrítica e discrição a fim de não ferir suscetibilidades e cometer injustiças muitas vezes irreparáveis."

Aduz, logo a seguir :

"Por isso mesmo é necessário esclarecer o auditor de que sua tarefa não é, especificamente, apurar irregularidades se bem que ele deva possuir qualidades técnicas e de percepção que the permitam ajuizar da regularidade dos documentos examinados ou dos atos realizados pelos administradores. Insistimos, entretanto, que é necessário desvincular do auditor a imagem do "detetive". Isso permitirá que execute melhor sua missão." (5)

Essa lição do consagrado Professor Boucinhas, dá-nos, em seu duplo aspecto, o exato entendimento da ação controladora, exercida através da auditoria, e o juízo que se deve fazer do auditor não excluido o comportamento a ser adotado por esse último objetivando o êxito de sua tarefa.

Por fim, não deve passar despercebida, para melhor compreensão do tema ora enfocado, a experiência de dois renomados técnicos, autores de premiada monografia, que, a certa altura de seu relevante trabalho, prelecionam:

"A auditoria, quando criteriosamente dirigida, acarreta uma série de vantagens à administração, entre as quais podem ser citadas :

a) fiscaliza metodicamente as operações administrativas a fim de verificar sua exatidão;

b) orienta a realização das múltiplas tarefas de administração com o intuito de evitar ou corrigir falhas, erros ou fraudes; 
c) fomenta entre o pessoal a vontade psicológica de oferecer a máxima contribuição, o maior esforço, para o eficiente e eficaz funcionamento da organização e consecução das atividades-fins;

d) leva a efeito o treinamento informal do funcionário no próprio local de trabalho." (6)

Com efeito, o Sistema de Pessoal Civil da Administração Federal já introduziu alterações no comportamento administrativo de muitas unidades de pessoal, tendo contribuído eficazmente para orientar as decisões dos dirigentes dessas unidades. A eficiência do sistema terá como condicionante a eficácia do controle pela Auditoria que, no momento oportuno, poderá identificar distorções e fornecer ao órgão central elementos para as correções de natureza técnica que a realidade administrativa recomende.

"A institucionalização da Auditoria de Pessoal, na área da Administração de Pessoal Federal, é efetivamente uma inovação no inovador SIPEC. Mas tanto ela quanto ele, temos a plena convicção disso, serão inovações meliorativas. E mais, muito mais que isso: serão instrumentos necessários à eficácia que todos desejamos para os serviços governamentais. Vamos assim, criando as condições indispensáveis à produtividade ótima e aos competentes suportes operacionais. (7)

\section{B I B L I O G R A F I A}

(1) F. de P. Hanika - Verso uma scienza della gestione d'imprensa. Ed. Etas Kompas, p. 8, apud Michele Calimeri, in RSP, vol. $105-n .^{\circ} 1$, Pág. 85 - CENDOC.

(2) Murilo Moreira da Silva - Administração de Pessoal e Orçamento, 1968, (Apontamentos de aula do Curso de Aperfeiçoamento de Assessores).

(3) Prof. João Luis Ney - Mobilização para a Reforma Administrativa Coleção Estudos, DASP, CENDOC, 1972.

(4) Ministro Iberê Gilson - "Auditoria : Técnica a Serviço do Controle" Revista do Serviço Público, vol. 106, pág. 26 - CENDOC.

(5) Prof. José da Costa Boucinhas - Seminário de Auditoria e Controles na Administração Pública, São Paulo, 1969.

(6) Sali Szajnferber e Vicente Ferrer Correia Lima - Administração: Generalidades e seus Instrumentos - Coleção Estudos, DASP, CENDOC, 1971.

(7) Prof. Glauco Lessa - Auditoria de Pessoal no SIPEC - O Auditor Aula inaugural do Curso de Formação de Auditores do SIPEC, 1972. 


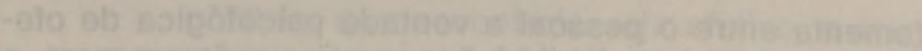

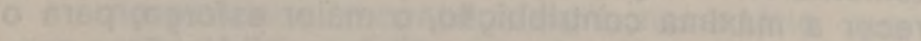

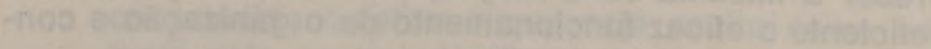

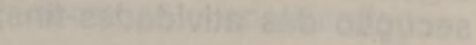

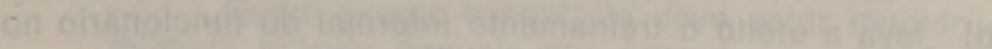

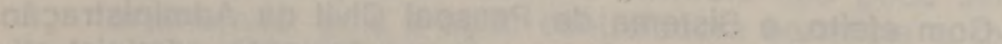

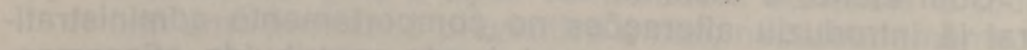

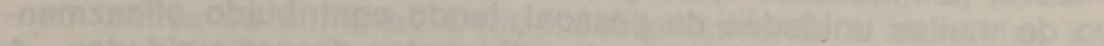

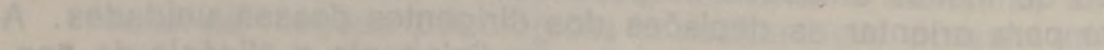

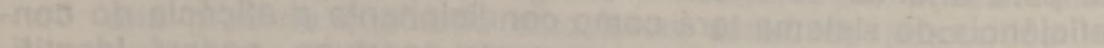

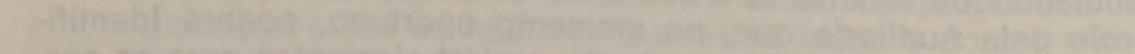

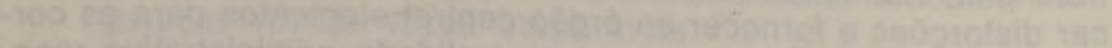

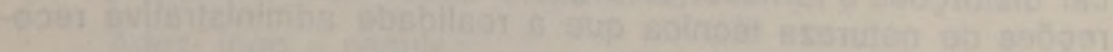

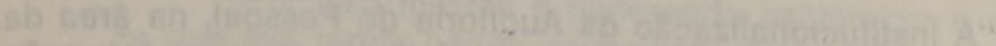

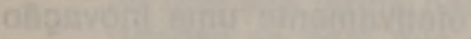

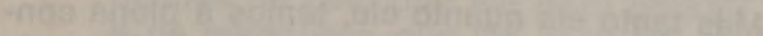

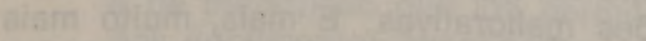

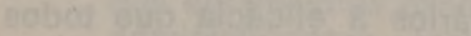

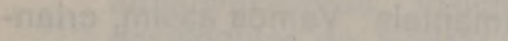

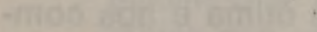

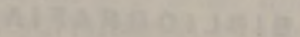

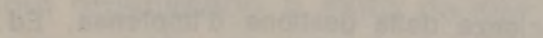

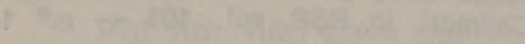

(3) 19

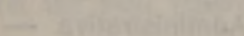

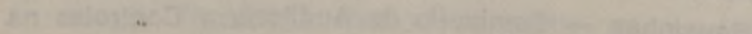

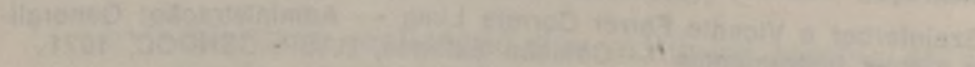

-

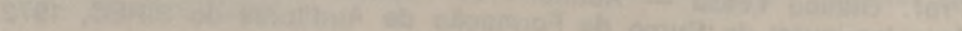

